\title{
Fraction Extraction of Orange Peel with Three Organic Solvents under Ultrasonic
}

\author{
Di Feng ${ }^{a}$, Xiaolu Wu ${ }^{\text {b }}$, Lu Cao ${ }^{\mathrm{c}}$, and Guizhen Gong ${ }^{\text {* }}$ \\ School of Chemical Engineering, Xuzhou University of technology, Xuzhou 221018, China \\ a1290865003@qq.com, b841463157@qq.com, '1062656800@qq.com,, ${ }^{\text {d }}$ ggz72@163.com \\ * The Corresponding Author \\ Keywords: Orange peel; Ethanol; Acetone; Petroleum ether; FTIR
}

\begin{abstract}
Fraction extraction of orange peel with ethanol, acetone and petroleum ether under ultrasonic were investigated. The extracts were detected and analyzed with infrared spectrum analysis (FTIR). The total yield of ethanol extraction was $33.6 \%$, acetone $27.3 \%$, and petroleum $22.3 \%$. Of the three solvents, the extraction effect of ethanol is the best, the worst of petroleum ether and the middle of acetone. FTIR analysis showed that compounds containing $\mathrm{OH}$, fatty hydrocarbon $\mathrm{C}-\mathrm{H}$ structure, $\mathrm{C}=\mathrm{O}$ group, lignin and $\mathrm{C}-\mathrm{O}$ groups can be enriched. The research has important basic theoretical significance in developing orange peel with high added value.
\end{abstract}

\section{Introduction}

Oranges are the most productive fruits in the world, and are also the second largest fruit in China. In 2014, output of orange juice was 2381 tons [1]. About $40 \%$ to $50 \%$ of the peel is produced [2]. Except for a very small proportion of which was used as medicines, most of the orange peel is discarded as garbage, which wastes both available resources and environmental pollution. The orange peel is mainly composed of cellulose, pectin and lignin. The effective ingredients can be used as a flavouring agent of food, candy, beverage, and it is also an important raw material of cosmetics and medicine [3-5]. At present, bioactive ingredients in orange peel have been developed at China and abroad. They are mainly active ingredients such as flavonoids, pectin and natural pigments. The methods of extracting compounds from orange peel mainly include supercritical fluid extraction, ultrasonic method, microwave extraction, organic solvent extraction and so on [6]. Compared with the conventional extraction, ultrasonic assisted extraction has rapid extraction, greatly shorten the experiment time, extraction process, low cost, better extraction effect, the operation is more simple, the most important is the extraction of stable, high extraction efficiency. The reason is that ultrasonic extraction is the use of ultrasonic radiation pressure produced by strong mechanical vibration, disturbance effect and cavitation effect.

In this paper, orange peel was extracted with ethanol, acetone and petroleum ether under ultrasonic assisted to study its organic structure and provide theoretical basis for its high added value.

\section{Experimental}

Materials. Orange peel used in this study was collected from Xuzhou city, Jiangsu, China. It was washed with de-ionized water, and dried in an oven at $60{ }^{\circ} \mathrm{C}$ for $10 \mathrm{~h}$, then which was ground to pass through 60 mesh sieve and stored in a desiccator at room temperature before using. All chemicals used in the experiment are analytical grade, obtained from the commercial source, and were used without further purification.

Experimental Method. $3.0 \mathrm{~g}$ orange peel dried and $100 \mathrm{ml} 95 \%$ ethanol were added into three necked bottle and extracted for $1.5 \mathrm{~h}$ under ultrasonic at room temperature. The extraction liquids were remove most of the solvent with a rotary evaporator under atmospheric pressure evaporation, then moved the concentrated liquid to the sample bottle, and the residual solvent evaporation to constant weight, and called extracts. The extracted residue was dried in a vacuum drying box and weighed. Then the next extraction were carried out, successively followed for 5 times. Orange peel were extracted with acetone and petroleum ether (PE) in accordance with the same conditions. 
The extracts gained were analyzed by FTIR spectroscopy (Alpha, Bruker company, German) using potassium bromide tableting method over a scan range of 500 to $4000 \mathrm{~cm}^{-1}$.

\section{Results and Discussion}

Yield of Extraction. The curves of accumulative extraction yield were shown in Figure 1. Accumulative extraction yield of three organic solvents increased with the increase of the extraction time. The total extraction yield of ethanol was $33.6 \%$, acetone extraction $27.3 \%$, and PE extraction was $22.3 \%$. The extraction effect of ethanol is the best, acetone is the second, and PE is the worst.

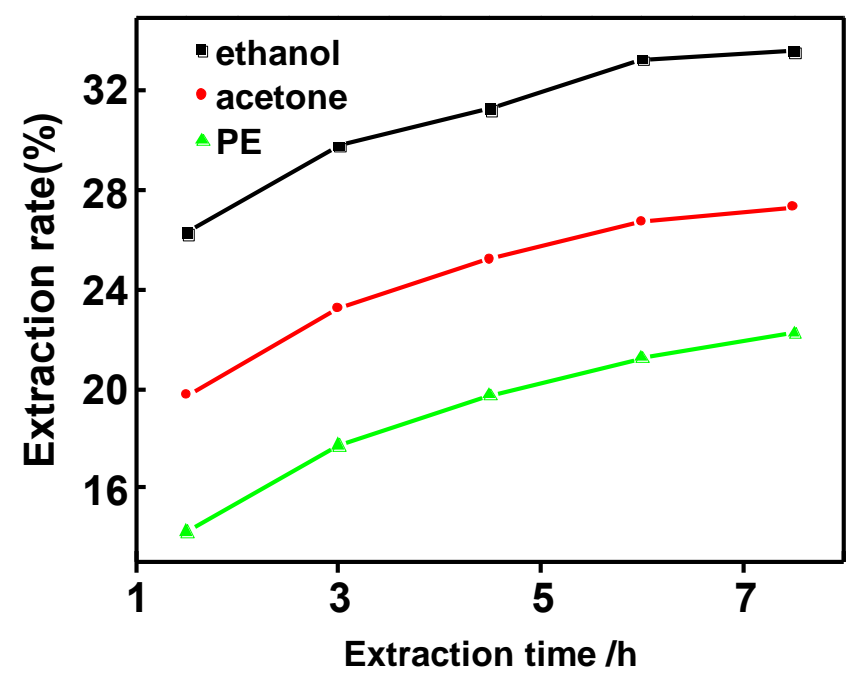

Figure 1. Yield of different solvent extracts

FTIR Analysis. FTIR spectra of fraction extracts of orange peel by three organic solvents are shown in Figure 2-4. As shown in Figures, The wide and strong absorption peak shown in 3400 $\mathrm{cm}^{-1}$ attributed to stretching vibration of hydroxyl group, which is the strongest absorption peak in three kinds of organic solvent extracts, showing a large number of hydroxyl groups enriched. The stretching vibration of $\mathrm{C}-\mathrm{H}$ in aliphatic $-\mathrm{CH}_{3}$ and $-\mathrm{CH}_{2}$ groups appear at $2925 \mathrm{~cm}^{-1}$ and $2827 \mathrm{~cm}^{-1}$, which increase with the increase of extraction time in the ethanol and PE extract, while in acetone extracts which decrease with prolonged time. The wave at $1750 \mathrm{~cm}^{-1}$ was corresponded to carbonyl bond, the absorption intensity of the peak is not much changed in all fraction extraction. The absorption peak about $1640 \mathrm{~cm}^{-1}$ is stretching vibration of $\mathrm{C}=\mathrm{O}$ in lignin, the absorption strength of which in each extracts is similar. Absorption at about $1210 \sim 1163 \mathrm{~cm}^{-1}$ was assigned to C-O asymmetry stretching, including alcohols, ethers, and esters bonds. Which increased gradually with prolong extraction time in three extract solvets.

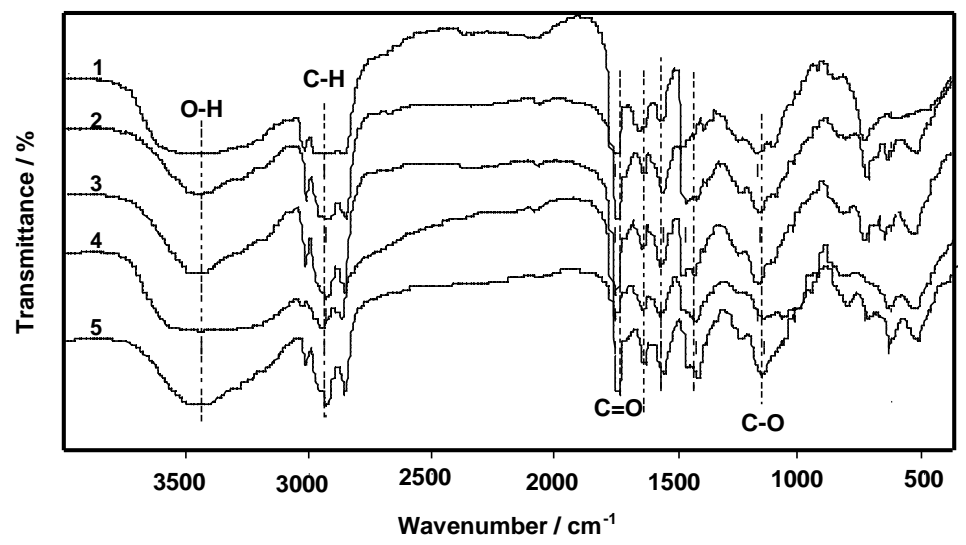

Figure 2. FTIR spectra of ethanol extraction 


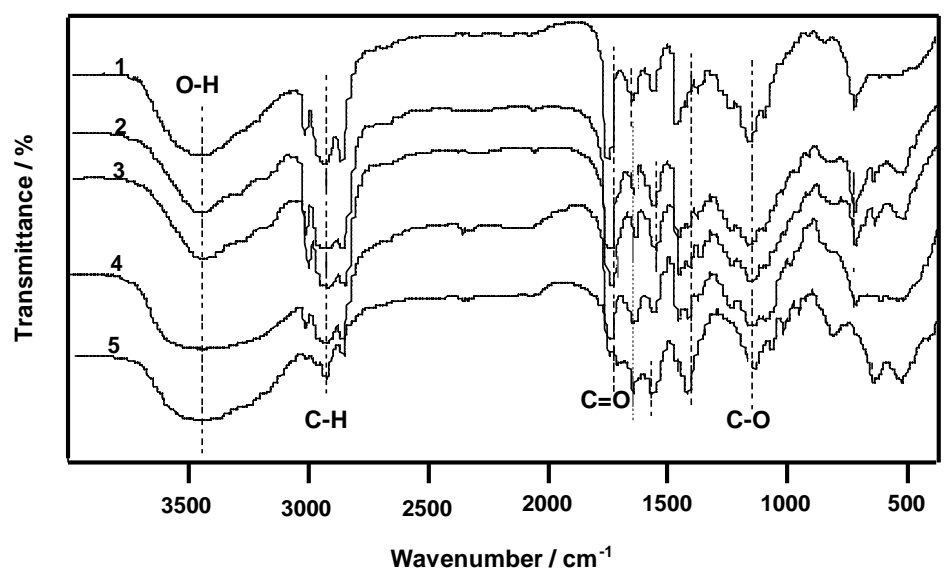

Figure 3. FTIR spectra of acetone extraction

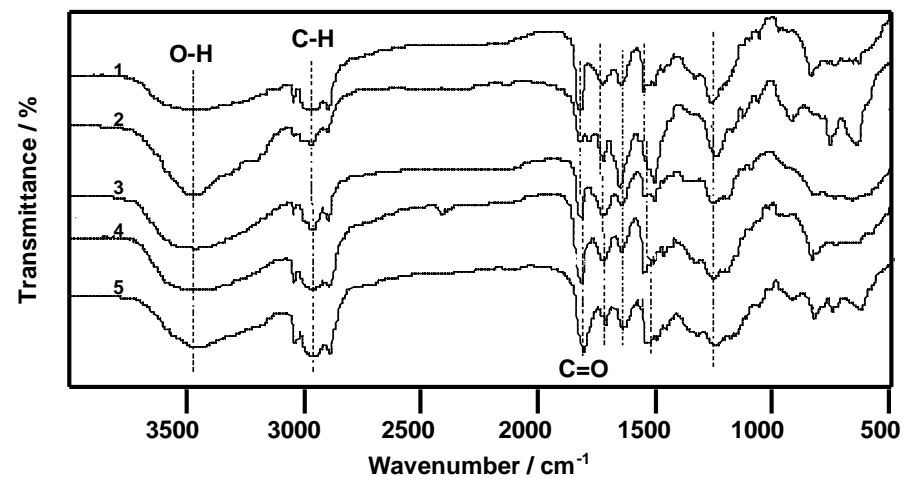

Figure 4. FTIR spectra of PE extraction

\section{Summary}

In this study, the fraction extraction of orange peel with ethanol, acetone and petroleum ether under ultrasonic were investigated. The total yield of ethanol extraction was $33.6 \%$, acetone $27.3 \%$, and petroleum ether $22.3 \%$. Of the three solvents, the extraction effect of ethanol is the best, the worst of petroleum ether and the middle of acetone. FTIR analysis showed that compounds containing $\mathrm{OH}$, fatty hydrocarbon $\mathrm{C}-\mathrm{H}$ structure, $\mathrm{C}=\mathrm{O}$ group, lignin and $\mathrm{C}-\mathrm{O}$ groups can be enriched. The research has important basic theoretical significance in developing orange peel with high added value.

\section{Acknowledgement}

This work was supported by the China Building Material Federation (2014-M3-4), Xuzhou Information Institute (XKQ016), Innovative Training Program for College Students of Xuzhou University of Technology (XCX2017155), Innovation and Entrepreneurship for College Students of Xuzhou University of Technology (2017042) and Open laboratory project of Xuzhou University of Technology (KF20170002 and KF20170003).

\section{References}

[1] Z. Fang and Y.X. Gao, Progress in research on utilization of the effective components in by-products of citrus process, China Food Additives. (2005) 9-13.

[2] X.X. Huang and Y.R. Zhang, Comprehensive utilization of orange peel, Forest by-product and Speciality in China. (2004) 40-42. 
[3] D.D. Majo, M. Giammanco, M.L. Guardia, E. Tripoli, S. Giammanco, E. Finotti, Flavanones in citrus fruit: Structure antioxidant activity relationships, Food Research International, Vol. 38(2005) 1161-1166.

[4] C.D. Sun, K.S. Chen and Y. Chen, Contents and antioxidant capacity of li-monin and nomilin in different tissues of citrus fruit of four cultivars during fruit growth and maturation, Food Chemistry, Vol. 93(2005) $599-605$.

[5] H.B. Wang, F.A. Wang and C.D Pan, Study on improved pectin extraction method from orang Peel, Food Science. Vol. 28(2007) 136-141.

[6] L.Y. Wei, J.H. Wang, X.D. Zheng, D. Teng, Y.L. Yang, C.G. Cai, T.H. Feng ang F. Zhang, Studies on the extracting technical conditions of inulin from Jerusalem arti-choke tubers, Journal of Food Engineering, Vol. 79(2007) 1087 -1093.

[7] Peng L. Individual Choice and Reputation Distribution of Cooperative Behaviors among Heterogeneous Groups. Chaos, Solitons \& Fractals, 2015, 77: 39-46. 